\title{
Update on evidence for a genetic predisposition to cerebral vasospasm
}

\author{
Vini G. Khurana, M.D., Ph.D., Douglas J. Fox, M.D., Irene Meissner, M.D., \\ FREDRIC B. MEYER, M.D., AND ROBERT F. SPETZLER, M.D.
}

Division of Neurological Surgery, Barrow Neurological Institute, St. Joseph's Hospital and Medical Center, Phoenix, Arizona; and Departments of Neurology and Neurosurgery, Mayo Clinic, Rochester, Minnesota

\begin{abstract}
$\checkmark$ Considerable evidence links cerebral vasospasm to the decreased bioavailability of endothelial nitric oxide synthase (eNOS) after aneurysmal subarachnoid hemorrhage (SAH). In recent studies from the cardiology literature, researchers have suggested that a genetic predisposition to coronary vasospasm might develop as the result of a T-786C single nucleotide polymorphism (SNP) in the eNOS gene. The authors of this study attempted to determine if there may be a similar genetic predisposition toward cerebral vasospasm.

The authors prospectively identified 28 patients with Fisher Grade 3 SAH from a group of 51 consecutive patients with ruptured intracranial saccular aneurysms. Genomic DNA was isolated from a peripheral blood sample obtained with permission from each patient. Gene microarray technology was used to assay the samples for the presence and distribution of certain key eNOS gene polymorphisms. Clinical, radiological, and genomic data were analyzed. The finding of $e N O S \mathrm{~T}-786 \mathrm{C}$ SNP could be used to significantly differentiate between the presence and severity of cerebral vasospasm $(\mathrm{p}=0.04)$.

The findings from this preliminary study support similar findings in the coronary vasospasm literature as well as the hypothesis that a predisposition toward cerebral vasospasm may be related partially to genetic factors, which needs to be confirmed in a larger study. Such gene-based information may be important in rapidly identifying patients at increased risk of vasospasm after SAH, independent of their Fisher grade. In this article, the authors review key studies in this area.
\end{abstract}

\section{KEY WORDS • cerebral vasospasm • functional genomics • genetic polymorphism • nitric oxide synthase $\bullet$ subarachnoid hemorrhage}

$\mathrm{T}$ HE only accepted predictor for the occurrence of cerebral vasospasm after SAH is the amount of subarachnoid blood detected on head CT scans, which is classified as Fisher Grades 1 through 4..$^{5}$ Anecdotally, however, the occurrence and neurological effects of vasospasm have been found to vary markedly, even among patients with the same Fisher grade. Such observations raise the possibility that genes encoding key proteins implicated in cerebrovascular regulation may exhibit functionally significant variations that can account for individual differences in vasomotor integrity after aneurysmal rupture. That is, the possibility exists for a genetic susceptibility to cerebral vasospasm. This article is intended as an update on the evolving evidence supporting such a possibility.

\section{Data From the Coronary Vasospasm Literature}

The notion of genetic predisposition to coronary vasospasm or Prinzmetal angina has been present in the cardi-

Abbreviations used in this paper: APOE = apolipoprotein E; $\mathrm{CT}=$ computed tomography; eNOS = endothelial nitric oxide synthase; $\mathrm{ET}-1=$ endothelin-1; $\mathrm{NO}=$ nitric oxide $; \mathrm{SAH}=$ subarachnoid hemorrhage; SNP = single nucleotide polymorphism. ac literature for decades. ${ }^{23}$ The higher incidence of coronary vasospasm in Japanese individuals compared with Caucasians ${ }^{27,37}$ and isolated reports of vasospastic angina in siblings ${ }^{6,32}$ have supported this notion. The idea is further strengthened by evidence from large epidemiological studies involving several hundred monozygotic and dizygotic twin pairs ${ }^{36}$ in addition to cohorts of unrelated individuals. ${ }^{26}$

Molecular evidence for a genetic predisposition to coronary vasospasm has been the subject of several studies. In some of these studies, individual variations or polymorphisms in the eNOS gene have been reported.2,7,27,38,39 Although certain other candidate genes, including those related to oxidative stress, ${ }^{22,26}$ have been implicated as the cause of a predisposition to coronary vasospasm, the eNOS gene is the strongest candidate.

Nakayama, et al., ${ }^{27}$ reported that the incidence of SNP in the T-786C eNOS gene was significantly higher in patients with coronary vasospasm than in matched control volunteers. The aberrant allele was found to be cytosine. In the same study, this polymorphism was, in vitro at least, associated with a significant reduction in $e N O S$ gene promoter activity. The presence of this polymorphism also is associated with increased basal tone of coronary arteries in vitro and with enhancement of these vessels' contractile 
response to acetylcholine in vivo. ${ }^{38,39}$ Reduced eNOS protein expression and enzymatic activity also have been reported to be associated with eNOS polymorphisms, including the T-786C SNP. ${ }^{31}$ Together, these clinical and molecular genetic data substantially implicate the involvement of the polymorphic eNOS gene in causing a susceptibility to coronary vasospasm. Although the pathogenesis of coronary vasospasm and cerebral vasospasm is dissimilar, impairment in NO signaling has been implicated in both. ${ }^{11,13,15}$

\section{Putative Predictors of Cerebral Vasospasm}

Risk factors for cerebral vasospasm include having a Fisher grade of SAH as exhibited on CT scans, ${ }^{5}$ young age, and a history of smoking. ${ }^{29}$ However, only the Fisher grade has widely accepted predictive value. Nonetheless, the anecdotal and independent observations of many physicians have been that the radiological confirmation and clinical severity of vasospasm are often unrelated to the amount of subarachnoid blood present on a patient's initial head CT scan. We clinically confirmed and quantified such observations. In a prospective study of 51 consecutive patients with aneurysmal SAH from ruptured saccular aneurysms,${ }^{15}$ we found 23 patients with Fisher Grade 1, 2, or $4 \mathrm{SAH}$ (that is, grades typically not strongly associated with the development of cerebral vasospasm). Of these 23 patients, radiologically confirmed vasospasm, clinically confirmed vasospasm, or both developed in seven (30\%). Of the 28 patients with Fisher Grade 3 SAH (that is, a grade typically strongly associated with the development of cerebral vasospasm), seven (25\%) experienced no radiologically or clinically confirmed vasospasm. Such observations spurred our interest in studying other factors that might be related to a predisposition toward this condition.

\section{Why Study the eNOS Gene?}

Of the array of molecular candidates potentially relevant to the pathogenesis of aneurysmal SAH, we deliberately chose the gene encoding the endothelial isoform of NOS as the focus of our investigation for several reasons. First, NO derived from constitutive isoforms of NOS acts as a potent vasodilator and inhibitor of inflammation, smoothmuscle cell proliferation, and platelet aggregation. ${ }^{4,25} \mathrm{Sec}-$ ond, there is biochemical, immunohistochemical, and functional evidence for impairment of NO signaling after induced SAH in experimental animals, ${ }^{11,13,35}$ and abnormal NO levels in cerebrospinal fluid have been reported in humans following aneurysmal SAH. ${ }^{30}$ Third, in gene transfer paradigms ${ }^{12}$ (recombinant) eNOS overexpression in animal $^{13}$ and human ${ }^{14}$ intracranial arteries, even in the setting of induced SAH in experimental animals, has been shown to be vasoprotective. Fourth, the eNOS gene knockout in animals has been shown to result in a predisposition to hypertension, atherosclerosis, coronary artery disease, and aortic aneurysm formation. ${ }^{17}$ Fifth, the inducible isoform of NOS and metabolically uncoupled eNOS can generate free radicals that adversely affect the structure and function of vessel walls. ${ }^{8,25}$ Last, the results of several studies have shown that the gene encoding eNOS, which is located on chromosome 7q35-36, ${ }^{21}$ is polymorphic in humans and that the presence of certain eNOS polymorphisms may increase susceptibility to conditions such as atherosclerosis, hypertension, myocardial infarction, coronary vasospasm, and the formation of abdominal aortic aneurysms (Table 1). ${ }^{9}, 10,16,19,27,33,34$

\section{Recent Evidence for Genetic Predisposition to Cerebral Vasospasm}

\section{Predisposition for Vasospasm Related to eNOS}

We studied 51 consecutive patients in whom aneurysmal SAH was diagnosed based on their histories and radiological findings, including both admission head CT scans and four-vessel cerebral angiography images. ${ }^{15}$ All patients were followed up clinically and radiologically, including the use of serial transcranial Doppler ultrasonography in each case, from the time of admission to the time of discharge (mean $22 \pm 10$ days). Forty-six patients (90\%) were admitted within 48 hours of their initial hemorrhage. All patients with SAH were treated in a neurolog$\mathrm{ical} /$ neurosurgical intensive care unit according to established clinical protocols. Each patient gave permission for sampling of genomic DNA. The genomic DNA from a venous blood sample obtained in each patient was assayed for three eNOS gene polymorphisms relevant to cardiovascular disease, including the T-786C SNP implicated in coronary vasospasm. The presence and severity of cerebral vasospasm were clinically determined using serial comprehensive neurological examinations and radiologically confirmed using serial transcranial Doppler ultrasonography and, when indicated, repeated cerebral angiography. Cerebral vasospasm was classified as being absent (no clinically or radiologically confirmed abnormality), asymptomatic but present (radiologically confirmed abnormality only), or symptomatically present (both clinically and radiologically confirmed abnormalities). We defined symptomatic vasospasm to include the delayed occurrence of confusion, aphasia, obtundation, or new motor deficit in the absence of other pharmacological, metabolic, or structural causes and with radiological confirmation.

Of the 51 patients, 28 presented with Fisher Grade 3 SAH. Among these 28 patients, the eNOS T-786C SNP significantly differentiated between the presence and severity of cerebral vasospasm $(p=0.04)$. Among these 28 patients, 21 experienced cerebral vasospasm. Of these 21, 19 (90\%) were cytosine allele heterozygous (T/C; 18 patients) or cytosine allele homozygous (C/C; one patient) for this SNP. The cytosine allele, reported to be the abnormal allele that causes a predisposition toward coronary vasospasm, ${ }^{27}$ occurred in four $(57 \%)$ of the seven patients without cerebral vasospasm, in eight $(80 \%)$ of the 10 patients with asymptomatic cerebral vasospasm, and in all 11 patients with symptomatic cerebral vasospasm. This trend was significant $(p=0.046)$. Among the 28 patients with Fisher Grade $3 \mathrm{SAH}$, the odds ratio for spasm for those with at least one cytosine allele was 7.1 (95\% confidence interval $0.88-57.5, \mathrm{p}=0.065$ ). These findings are preliminary in that they need to be confirmed in a larger cooperative study. However, they do support the findings of Nakayama, et al., ${ }^{27}$ indicating that there might be a genetic susceptibility to vasospasm, particularly one involving the T-786C SNP of the eNOS gene. 


\section{Actions and Effects of Apolipoprotein E}

Apolipoprotein $\mathrm{E}$ is a protein that is a component of very-low-density lipoproteins involved in cholesterol transport. The APOE is encoded by the polymorphic gene $A P O E$ on chromosome $19 \mathrm{q} 13 .^{3}$ The most common allele of this gene is the epsilon 3 allele (APOE e3), encoding APOE e3. The presence of the less common epsilon 4 allele of this gene ( $A P O E$ e4), encoding APOE e4, has been implicated in causing susceptibility to hyperlipoproteinemia Type III, coronary artery disease, oxidative stress, Alzheimer disease, and modulation of ET-1-mediated vasoconstriction. ${ }^{28}$ Recently, Lanterna, et al., ${ }^{18}$ reported that the presence of the $A P O E$ e 4 allele in patients with SAH negatively affected their overall cognitive morbidity, conferred a greater likelihood of their experiencing cerebral vasospasm, and increased their susceptibility to neurological impairment from vasospasm. These findings were based on a prospective study of 101 patients with Hunt and Hess Grades I to III who were admitted after aneurysmal SAH. The researchers used an $A P O E$ allele genotyping assay of genomic DNA purified from peripheral blood samples in addition to serial tests of cognitive
TABLE 1

Polymorphic genes implicated in susceptibility to cerebral vasospasm*

\begin{tabular}{lcc}
\hline $\begin{array}{l}\text { Protein Encoded } \\
\text { by PMG }\end{array}$ & $\begin{array}{c}\text { PMG on } \\
\text { Chromosome }\end{array}$ & Associated Conditions \\
\hline eNOS & $7 q 35$ & $\begin{array}{c}\text { atherosclerosis, coronary artery disease, } \\
\text { hypertension, cerebral vasospasm } \\
\text { Alzheimer disease, coronary artery } \\
\text { disease, hyperlipoproteinemia } \\
\text { Type III, cerebral vasospasm }\end{array}$ \\
haptoglobin & $19 \mathrm{q} 13$ & $\begin{array}{c}\text { atherosclerosis, coronary artery disease } \\
\text { cerebral vasospasm }\end{array}$ \\
\hline
\end{tabular}

* PMG = polymorphic gene.

and functional outcome. The clinical characteristics of their patient cohort in terms of ruptured aneurysm site and size distribution were consistent with other published series. The authors postulated that the adverse effects of APOE e4 in patients with SAH may be due to it being a less efficient free-radical scavenger and a modulator of amyloid-beta protein and ET-1-mediated vasospasm. ${ }^{18,28}$

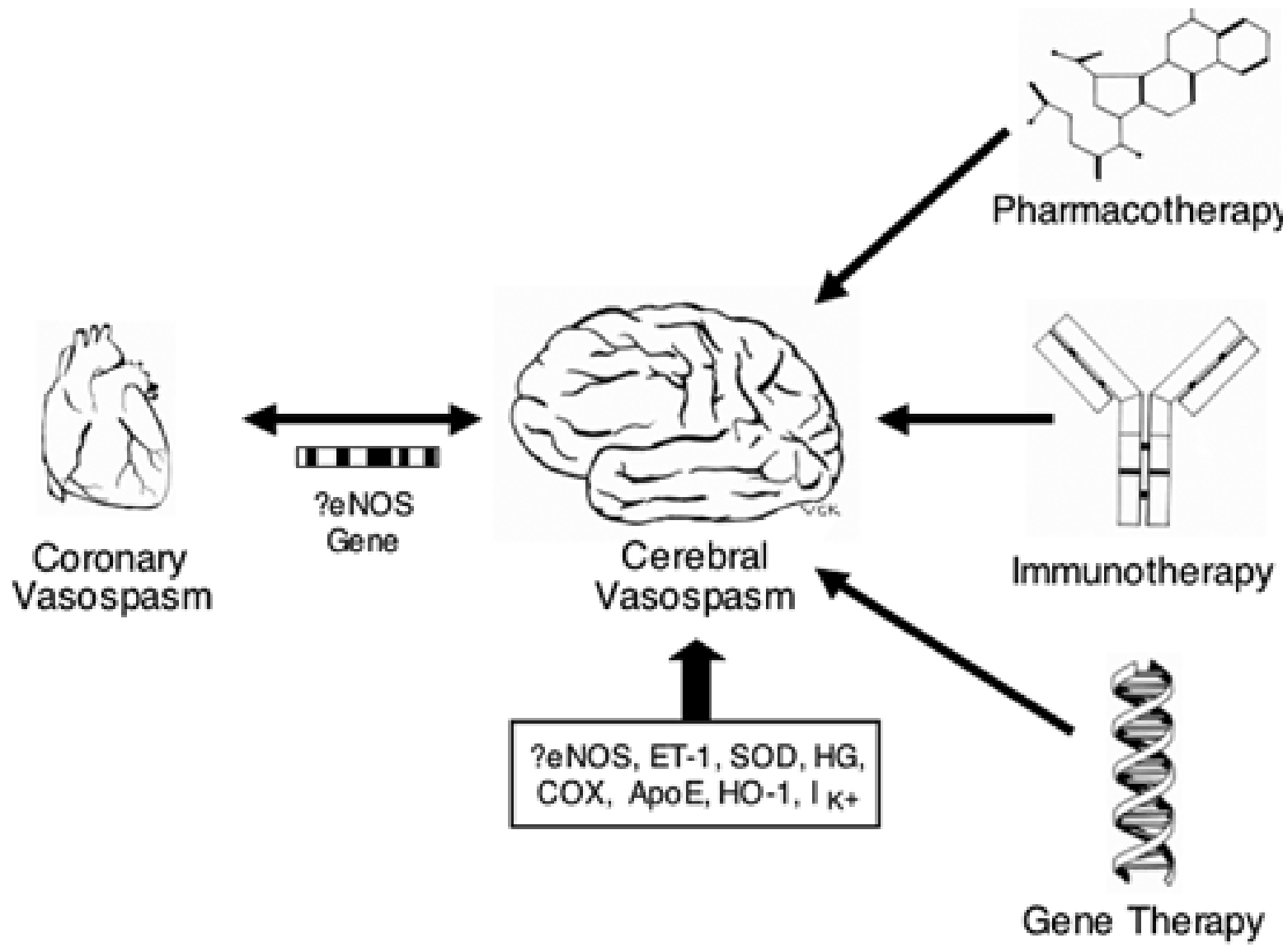

FIG. 1. Schematic drawing. Findings from recent coronary and cerebral vasospasm human genomics studies implicate the $e N O S$ gene as a potential "vasospasm-susceptibility gene." However, several putative molecules are implicated in the pathogenesis of cerebral vasospasm (shown in the boxed area). Their encoding genes, if polymorphic, should also be considered as part of a polygenic vasospasm-susceptibility model. Identification of the precise molecular basis for vasospasm, including any susceptibility genes, should pave the way to individually tailored pharmacotherapy, immunotherapy, and/or gene therapy. $\mathrm{COX}=$ cyclooxygenase; $\mathrm{HG}=$ haptoglobin; $\mathrm{HO}-1=$ hemeoxygenase- $1 ; \mathrm{I}_{\mathrm{K}+}=$ potassium channel-mediated current; SOD = superoxide dismutase. 


\section{Actions and Effects of Haptoglobin}

Haptoglobin is composed of two subunits, alpha and beta. The former subunit is encoded by the haptoglobin alpha gene and the latter by the haptoglobin beta gene. The gene complex is located on chromosome 16q22.24 The haptoglobin alpha gene is dimorphic, encoding alpha 1 and alpha 2 variants of the alpha subunit. Haptoglobin containing the alpha 2 subunit is less capable of inhibiting hemoglobin-induced free-radical production, and it promotes inflammatory responses in vitro. Haptoglobin polymorphism has been implicated as a cause of susceptibility to atherosclerotic coronary artery disease. ${ }^{20}$ Researchers have recently suggested that knowing the haptoglobin subtype of a patient may be helpful in predicting the occurrence of cerebral vasospasm. Borsody, et al., ${ }^{1}$ postulated that types of haptoglobin that have greater affinity for extracorpuscular hemoglobin could neutralize the effects of hemoglobin, which induces cerebral vasospasm. These authors studied 32 patients with Fisher Grade 3 SAH and used genotyping to identify their haptoglobin alleles. Vasospasm was significantly more common in patients with the alpha 2 allele than in those with the alpha 1 allele. Furthermore, the risk of vasospasm among patients with the alpha 1/alpha 1 genotype was unexpectedly low for those with Fisher Grade 3 SAH, suggesting that the haptoglobin variant encoded by this genotype confers protection against vasospasm. ${ }^{1,29}$

\section{Conclusions}

The three independent studies of the functional genomics of cerebral vasospasm that we have described have several important clinical implications (Table 1). First, the volume and distribution alone of subarachnoid blood on a CT scan (that is, the Fisher grade) are not the sole factors governing predisposition to cerebral vasospasm after SAH. Rather, genetic factors that are specific to individuals may also govern such a predisposition. Second, if a subset of patients with SAH can be defined by identifying a genetic profile linked to increased vasospasm susceptibility, these patients can be observed more closely and treated more aggressively when appropriate. Third, elucidating the precise molecular pathogenesis of cerebral vasospasm, which probably involves multiple proteins and their encoding genes, will be key to tailoring more effective therapy. Tailored treatment options may involve pharmacotherapy, immunotherapy, and/or gene therapy (Fig. 1). Finally, the findings in these studies need to be confirmed by larger series.

\section{References}

1. Borsody M, Burke A, Coplin W, Miller-Lotan R, Levy A: Haptoglobin and the development of cerebral artery vasospasm after subarachnoid hemorrhage. Neurology 66:634-640, 2006

2. Chang K, Baek SH, Seung KB, Kim PJ, Ihm SH, Chae JS, et al: The Glu298Asp polymorphism in the endothelial nitric oxide synthase gene is strongly associated with coronary spasm. Coron Artery Dis 14:293-299, 2003

3. Chartier-Harlin MC, Parfitt M, Legrain S, Perez-Tur J, Brousseau T, Evans A, et al: Apolipoprotein E, epsilon 4 allele as a major risk factor for sporadic early and late-onset forms of
Alzheimer's disease: analysis of the 19q13.2 chromosomal region. Hum Mol Genet 3:569-574, 1994

4. Dalkara T, Moskowitz MA: Nitric oxide and the cerebral circulation, in Welch KMA, Caplan LR, Reis DJ, et al (eds): Primer on Cerebrovascular Diseases. San Diego: Academic Press, 1997, pp 96-98

5. Fisher CM, Kistler JP, Davis JM: Relation of cerebral vasospasm to subarachnoid hemorrhage visualized by computerized tomographic scanning. Neurosurgery 6:1-9, 1980

6. Fujiwara Y, Yamanaka O, Nakamura T, Yamaguchi H: Coronary spasm in two sisters. Jpn Circ J 57:472-474, 1993

7. Fukuda N, Kurokawa S, Maeda K, Iseki S, Takahasi M, Niwano $\mathrm{H}$, et al: A young girl with vasospastic angina associated with mutation in endothelial nitric oxide synthase gene-a case report. Angiology 54:233-237, 2003

8. Guzik TJ, West NE, Pillai R, Taggart DP, Channon KM: Nitric oxide modulates superoxide release and peroxynitrite formation in human blood vessels. Hypertension 39: 1088-1094, 2002

9. Hingorani AD: Polymorphisms in endothelial nitric oxide synthase and atherogenesis: John French Lecture 2001. Atherosclerosis 154:521-527, 2001

10. Hingorani AD, Liang CF, Fatibene J, Lyon A, Monteith S, Parsons A, et al: A common variant of the endothelial nitric oxide synthase ( $\mathrm{Glu}^{298} \rightarrow$ Asp) is a major risk factor for coronary artery disease in the UK. Circulation 100:1515-1520, 1999

11. Khurana VG, Besser M: Pathophysiological basis of cerebral vasospasm following aneurysmal subarachnoid haemorrhage. J Clin Neurosci 4:122-131, 1997

12. Khurana VG, Meyer FB: Translational paradigms in cerebrovascular gene transfer. J Cereb Blood Flow Metab 23: 1251-1262, 2003

13. Khurana VG, Smith LA, Baker TA, Eguchi D, O'Brien T, Katusic ZS: Protective vasomotor effects of in vivo recombinant endothelial nitric oxide synthase gene expression in a canine model of cerebral vasospasm. Stroke 33:782-789, 2002

14. Khurana VG, Smith LA, Weiler DA, Springett MJ, Parisi JE, Meyer FB, et al: Adenovirus-mediated gene transfer to human cerebral arteries. J Cereb Blood Flow Metab 20:1360-1371, 2000

15. Khurana VG, Sohni YR, Mangrum WI, McClelland RL, O'Kane DJ, Meyer FB, et al: Endothelial nitric oxide synthase gene polymorphisms predict susceptibility to aneurysmal subarachnoid hemorrhage and cerebral vasospasm. J Cereb Blood Flow Metab 24:291-297, 2004

16. Kotani K, Shimomura T, Murakami F, Ikawa S, Kanaoka Y, Ohgi S, et al: Allele frequency of human endothelial nitric oxide synthase gene polymorphism in abdominal aortic aneurysm. Intern Med 39:537-539, 2000

17. Kuhlencordt PJ, Gyurko R, Han F, Scherrer-Crosbie M, Aretz $\mathrm{TH}$, Hajjar R, et al: Accelerated atherosclerosis, aortic aneurysm formation, and ischemic heart disease in apolipoprotein E/endothelial nitric oxide synthase double-knockout mice. Circulation 104:448-454, 2001

18. Lanterna LA, Rigoldi M, Tredici G, Biroli F, Cesana C, Gaini $\mathrm{SM}$, et al: APOE influences vasospasm and cognition of noncomatose patients with subarachnoid hemorrhage. Neurology 64:1238-1244, 2005

19. Lembo G, De Luca N, Battagli C, Iovino G, Aretini A, Musicco $\mathrm{M}$, et al: A common variant of endothelial nitric oxide synthase (Glu298Asp) is an independent risk factor for carotid atherosclerosis. Stroke 32:735-740, 2001

20. Levy AP, Hochberg I, Jablonski K, Resnick HE, Lee ET, Best $\mathrm{L}$, et al: Haptoglobin phenotype is an independent risk factor for cardiovascular disease in individuals with diabetes: The Strong Heart Study. J Am Coll Cardiol 40:1984-1990, 2002

21. Marsden PA, Heng HH, Scherer SW, Stewart RJ, Hall AV, Shi $\mathrm{XM}$, et al: Structure and chromosomal localization of the human constitutive endothelial nitric oxide synthase gene. J Biol Chem 268:17478-17488, 1993 
22. Mashiba J, Koike G, Kamiunten H, Ikeda M, Sunagawa K: Vasospastic angina and microvascular angina are differentially influenced by PON1 A632G polymorphism in the Japanese. Circ J 69: 1466-1471, 2005

23. Mauritson DR, Peshock RM, Winniford MD, Stern L, Johnson SM, Hillis LD: Prinzmetal's variant angina: is it transmitted genetically? Am Heart J 105: 1049, 1983

24. McGill JR, Yang F, Baldwin WD, Brune JL, Barnett DR, Bowman $\mathrm{BH}$, et al: Localization of the haptoglobin alpha and beta genes (HPA and HPB) to human chromosome $16 \mathrm{q} 22$ by in situ hybridization. Cytogenet Cell Genet 38: $155-157,1984$

25. Moncada S, Palmer RMJ, Higgs EA: Nitric oxide: physiology, pathophysiology, and pharmacology. Pharmacol Rev 43: 109-142, 1991

26. Murase Y, Yamada Y, Hirashiki A, Ichihara S, Kanda H, Watarai $\mathrm{M}$, et al: Genetic risk and gene-environment interaction in coronary artery spasm in Japanese men and women. Eur Heart J 25:970-977, 2004

27. Nakayama M, Yasue $H$, Yoshimura M, Shimasaki $Y$, Kugiyama K, Ogawa $\mathrm{H}$, et al: T-786 $\rightarrow \mathrm{C}$ mutation in the $5^{\prime}$ flanking region of the endothelial nitric oxide synthase gene is associated with coronary spasm. Circulation 99:2864-2870, 1999

28. Paris D, Town T, Parker TA, Humphrey J, Mullan M: Isoformspecific vasoconstriction induced by apolipoprotein $\mathrm{E}$ and modulation of this effect by Alzheimer's beta-amyloid peptide. Neurosci Lett 256:73-76, 1998

29. Rabinstein AA: The blood and the vessel: prediction of cerebral vasospasm after subarachnoid hemorrhage. Neurology 66: 622-623, 2006

30. Sadamitsu D, Kuroda Y, Nagamitsu T, Tsuruta R, Inoue T, Ueda T, et al: Cerebrospinal fluid and plasma concentrations of nitric oxide metabolites in postoperative patients with subarachnoid hemorrhage. Crit Care Med 29:77-79, 2001

31. Song J, Yoon Y, Park KU, Park J, Hong YJ, Hong SH, et al:
Genotype-specific influence on nitric oxide synthase gene expression, protein concentrations, and enzyme activity in cultured human endothelial cells. Clin Chem 49:847-852, 2003

32. Tachibana K, Kazatani Y, Kodama K, Matsuzaki K, Murakami E, Kokubu T: Vasospastic angina in two sisters. Jpn Heart J 36:669-673, 1995

33. Wang XL, Sim AS, Badenhop RF, McCredie RM, Wilcken DEL: A smoking-dependent risk of coronary artery disease associated with a polymorphism of the endothelial nitric oxide synthase gene. Nat Med 2:41-45, 1996

34. Wang XL, Wang J: Endothelial nitric oxide synthase gene sequence variations and vascular disease. Mol Genet Metab 70:241-251, 2000

35. Weir B, MacDonald L: Cerebral vasospasm. Clin Neurosurg 40:40-55, 1993

36. Williams FM, Cherkas LF, Spector TD, MacGregor AJ: A common genetic factor underlies hypertension and other cardiovascular disorders. BMC Cardiovasc Disord 4:20, 2004

37. Yasue H, Kugiyama K: Coronary artery spasm: Japanese view. Coron Artery Dis 1:668-673, 1990

38. Yoshimura M, Nakayama M, Shimasaki Y, Ogawa H, Kugiyama K, Nakamura $S$, et al: A T-786C mutation in the 5 '-flanking region of the endothelial nitric oxide synthase gene and coronary arterial vasomotility. Am J Cardiol 85:710-714, 2000

39. Yoshimura M, Yasue H, Nakayama M, Shimasaki Y, Ogawa H, Kugiyama K, et al: Genetic risk factors for coronary artery spasm: significance of endothelial nitric oxide synthase gene T$786 \mathrm{C}$ and missense Glu298Asp variants. J Investig Med 48: 367-374, 2000

Manuscript received June 16, 2006.

Accepted in final form August 4, 2006.

Address reprint requests to: Vini G. Khurana, M.D., Ph.D., University of Sydney, Brain \& Mind Research Institute, 100 Mallett Street, Camperdown, NSW, 2050, Australia.email: neuropub@chw.edu. 